\title{
Age-Associated Changes in Histology and Gene-Expression Profile in the Rat Ventral Prostate
}

\author{
Kin-Mang Lau, Neville N. C. Tam, Christopher Thompson, Robert Y. S. Cheng, \\ Yuet-Kin Leung, and Shuk-Mei Ho
}

Department of Surgery (KML, NNCT, CT, YKL, SMH), Division of Urology, University of Massachusetts Medical School, Worcester, Massachusetts

\begin{abstract}
SUMMARY: The incidence of prostate diseases rises dramatically with age in men, yet little is understood of the mechanisms underlying prostatic senescence and its contribution to disease development in the gland. In Noble rats, aging of the ventral prostate (VP) is characterized morphologically by widespread atrophy of acini, increased accumulation of concretions in glandular lumen, infiltration of inflammatory cells, and focal epithelial atypia. We used a cDNA microarray containing 2388 known transcripts, together with the Tyramide Amplification System and $t$ statistics, to identify differentially expressed genes in the VPs of young ( 3 months old) and old (16 months old) rats. A total of 78 VP genes were found to be differentially expressed by the two groups; in old rats, 65 VP genes (83\%) showed reduced expression and 13 genes (17\%) showed increased expression compared with young animals. The age-dependent underexpressed genes fell into several functional clusters: those involved in amino-acid metabolism, protein synthesis, protein secretion and degradation, vesicle/membrane trafficking, energy metabolism, signal transduction, spermidine and spermine syntheses, and cellular defense against stress. The overexpressed genes included iduronate 2-sulfatase, HLA class I locus C heavy chain, membrane cofactor protein of the complement system, TRPM-2, cadherin-associated protein-related, and X-CGD. Post hoc analyses confirmed a progressive decline in the expression of ribophorin II and BiP and a gradual increase in the expression of TRPM-2 in rat VPs as animals aged from 3 to 19 months old. In conclusion, the observed widespread declines in expression of genes involved in protein synthesis, protein fidelity maintenance, anabolism, growth inhibition, and energy metabolism, together with increased expression of genes implicated in cell survival in the VPs of senescent rats, may help explain the susceptibility of the prostates of elderly men to development of disease. (Lab Invest 2003, 83:743-757).
\end{abstract}

$M$ en of advanced age have a propensity for the development of prostatic diseases such as benign prostatic hyperplasia and prostate cancer (Schulman, 2000). Senescence-associated changes in the prostate are believed to be contributing factors to the pathogenesis of these diseases. Andropause (Anawalt and Merriam, 2001), somatopause (Anawalt and Merriam, 2001), and altered estrogenic status (Griffiths, 2000) are associated with male aging. The hormonal sensitivity of the aged prostate also changes (Banerjee et al, 2001; Prins et al, 1996; SanchezVisconti et al, 1995). Other cellular changes, such as

\section{DOI: 10.1097/01.LAB.0000069519.06988.24}

Received March 13, 2003.

Research was supported, in part, by NIH grants CA15776, CA62269 and AG13965 awarded to SMH. Current address for Dr. Lau: Department of Anatomical and Cellular Pathology, The Chinese University of Hong Kong, The Prince of Wales Hospital, Shatin, New Territories, Hong Kong, SAR. Current address for Dr. Cheng: Laboratory of Comparative Carcinogenesis, National Cancer Institute at Frederick, NIH, Building 538, Room 206, Frederick, Maryland 21702. Current address for Dr. Thompson: CIIT Centers for Health Research, 6 Davis Drive, POB 12137, Research Triangle Park, North Carolina 27709-2137.

Address reprint requests to: Dr. Shuk-Mei Ho, Rm 504, Lazare Research Building, Department of Surgery, University of Massachusetts Medical School, 364 Plantation Street, Worcester, Massachusetts 01605. E-mail: Shuk-mei.Ho@umassmed.edu diminution of apoptotic potentials (Banerjee et al, 2000), increased expression of survival factors (Bettuzzi et al, 1994; Marinelli et al, 1994), loss of antioxidant enzyme activities (Ghatak and Ho, 1996), and accumulation of radical-induced DNA damages (Malins et al, 2001) found in prostates of senescent animals or elderly men all have been implicated as causative factors of prostatic diseases. Despite these findings, the mechanisms underlying prostatic senescence remain poorly understood and clearly warrant further investigation.

Expression-profiling technology has proven effective in elucidating mechanisms of aging in various bodily tissues (Weindruch et al, 2002). In a microarray study, aging of the gastrocnemius muscle was found to result in a gene-expression pattern suggestive of a marked stress response and to reduce the expression of metabolic and biosynthetic genes (Weindruch et al, 2001). When this technique was used to determine transcriptional profiles of the aging neocortex and cerebella of mice, a profile indicative of an inflammatory response, oxidative stress, and reduced neurotrophic support was noted in both brain regions (Lee et al, 2000). Using a similar approach, Cao and coworkers (2001) demonstrated that the aging of the liver was accompanied by changes in gene expression consistent with increased inflammation, cellular stress, and fibrosis and reduced capacity for apopto- 
sis, xenobiotic metabolism, normal cell-cycling, and DNA replication. Global gene profiling also revealed that the direction and magnitude of age-associated changes in gene expression differ in the colon and duodenum (Lee et al, 2001). Interestingly, genes associated with cancerous growth of the colon exhibited enhanced expression in the aging colon, providing a probable link between aging and carcinogenesis in this tissue. A crucial point illustrated by these geneprofiling studies is that the mechanisms of aging in each tissue are unique and not necessarily shared by different tissues.

In this study, a cDNA microarray containing 2388 known genes was used to detect senescenceassociated changes in gene expression in the ventral prostates (VPs) of Noble (NBL) rats. A posthybridization signal-amplification protocol, the Tyramide Signal Amplification (TSA) labeling system, was used to enhance quantification of low-abundance transcripts. After acquisition and normalization of data, $t$ statistics were used as an objective measure to determine differential expression (Callow et al, 2000). Approximately $78 \%$ (1882) of the genes in this array were expressed in the VP, but only $4 \%$ (78) of the genes exhibited differential expression as the NBL rats advanced in age. Transcriptional profiles in the VPs of aged rats reflect a physiologic state of reduced protein synthesis and turnover, relaxation of protein-fidelity checkpoints, disruption in vesicle/membrane trafficking, diminished energy metabolism, reduced polyamine synthesis, weakened cellular defense against stress, increased cell survival, and an increase in the infiltration of phagocytic cells. These findings provide clues to the molecular events mediating aging of the rat VP and also explain some of the morphologic changes observed in the VPs of aged rats.

\section{Results and Discussion}

\section{Morphologic Changes in VPs of NBL Rats as Animals Advanced in Age}

Up to approximately 8 months of age, the VPs of NBL rats appeared histologically normal. Tall columnar epithelial cells lined the prostatic acini, which were filled with a homogenous secretion (Fig. 1, A and B). Beginning at 9 months of age, the VPs showed focal atrophy of a small number of acini, lined with cuboidal cells, coexisting with morphologically normal acini (Fig. 1C). A significant reduction in the height and infoldings of epithelial cell was noted in the atrophic foci (Fig. 1D). Focal epithelial atypia, including intraepithelial vacuoles and atypical hyperplasia, involving only a small section of the acinar epithelium, were occasionally seen (Fig. 1E). The lumen of some acini was found to contain concretions (ie, corpora amylacea) (Fig. 1E). The incidence of infiltration of stromal inflammatory cells (macrophages, mast cells, and lymphocytes) was generally low in the VPs of 9-month-old animals but increased progressively with advancing age (Fig. 1, H and I). Likewise, the incidences of acini atrophy, epithelial atypia, atypical hyperplasia, and luminal concretions in the VPs gradually increased as rats advanced in age (Fig. 1, F and J). Diffuse atrophy (Fig. 1, G and $\mathrm{H}$ ) and widespread epithelial atypia and atypical hyperplasia (Fig. 1, G, K, and L) became common features of the aged VPs in 16- to 19-monthold rats.

The aforementioned morphologic changes in the VPs of senescent NBL rats are consistent with those reported for the prostates of aged $\mathrm{ACl}$, Copenhagen, and Wistar rats (Isaacs, 1984; Ward et al, 1980). Many of these age-dependent changes, particularly the development of diffuse atrophy of prostatic acini, are probably caused by a decline in circulating testosterone with aging in most rat strains (Isaacs, 1984). In $\mathrm{ACl}$ and Copenhagen rats, serum testosterone levels decline from 3 to $4 \mathrm{ng} / \mathrm{ml}$ to approximately $1 \mathrm{ng} / \mathrm{ml}$ between 8 and 16 months of age. Severe reduction in cytoplasmic volume of epithelial cells likely involves a highly regulated process, termed autophagy (Klionsky and Emr, 2000). Cytoplasm and organelles are sequestered and delivered to lysosomes or vacuoles for degradation and recycling. Another prominent feature observed in the VP of aged rat was an increase in the number of concretions, or corpora amylacea. Rudiments of apoptotic cells often are seen trapped in prostatic concretions. Overall, the morphologic features observed in the aged rat prostates are similar to those found in human benign prostatic hyperplasia specimens. These include basal-cell hyperplasia, atypical hyperplasia, atrophy-associated hyperplasia, and the common occurrence of corpora amylacea (Mittal et al, 1989). Interestingly, corpora amylacea is noticeably absent in cases of human carcinoma.

\section{Identification of Differentially Expressed Genes in VPs with Advancing Age in NBL Rats}

The TSA labeling and detection protocol was used to enhance signal intensities for the MICROMAX microarray analyses. Hybridization results demonstrated that $78 \%$ (1882) of the elements on the array consistently showed signal intensities 1.5-fold above background at both Cy3 and Cy5 channels after hybridization with labeled rat cDNAs. This set was considered "hits" or "expressed genes" in the rat VP. The rest of the elements (506 [22\%]) were too close to the background cutoff and therefore could not be considered true signals. The percentage of "hits" detected in this study was consistent with results obtained from another study using the TSA-labeling protocol (83\%) (Karsten et al, 2002). These percentages were markedly higher than those reported for studies not using an amplification system, which typically ranged between $30 \%$ and $45 \%$ for general or nontissue-specific microarrays (Ho and Lau, 2002). The TSA system was originally developed to permit microarray analyses with smaller amounts of RNA. It has been shown to reduce the total RNA requirement by 20 to 100 times to a range between 0.1 to $0.5 \mu \mathrm{g}$ (Karsten et al, 2002). In our study we found the protocol useful in increasing the percentage of "hits." In other words, it enhanced 

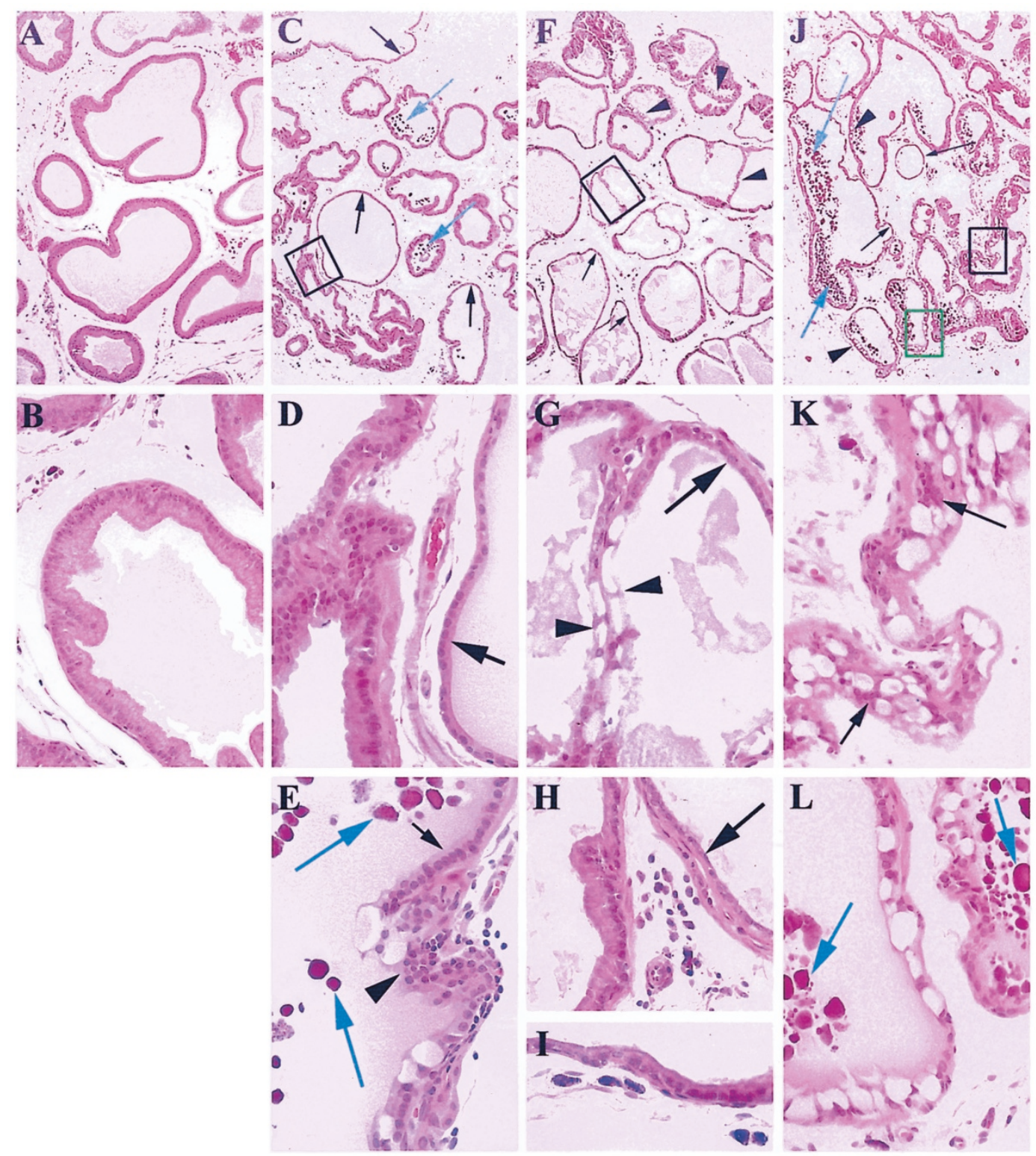

Figure 1.

(A-B) Ventral prostate (VP) of a 3-month-old male Noble rat. A, The acini are lined by tall columnar epithelial cells, and the lumens are filled with eosinophilic secretion (original magnification, $\times 12.5$ ). B, Glandular epithelium consists of tall columnar cells with basal-located nuclei (original magnification, $\times 93$ ). (C-E) VP of a 9-month-old male Noble rat. C, Focal atrophy is exhibited in all or a portion of acini (black arrows). Corpora amylacea were found within lumens (blue arrows) (original magnification, $\times 12.5$ ). D. High magnification of a region outlined in $\mathrm{C}$ demonstrates a normal acinus versus an atrophic gland lined by cuboidal cells (arrow) (original magnification, $\times 93$ ). E, Cellular atypia (arrowhead) characterized by a derangement of cells with vacuoles in epithelium, and this small lesion is contiguous with the normal tall columnar epithelium (arrow). Note the presence of corpora amylacea (blue arrows) in the lumen (original magnification, $\times 93$ ). (F-I) VP of a 16-month-old male Noble rat. F, Epithelium exhibits atrophy (arrows) and cellular atypia (arrowheads), which are widespread in the acini (original magnification, $\times 12.5)$. G, High magnification of a region outlined in $\mathrm{F}$ demonstrates a single acinus with both cellular atypia (arrowhead) and atrophy (arrow) (original magnification, $\times 93$ ). $\mathrm{H}$, Infiltration of inflammatory cells is seen in stroma but not within the lumen. Note the presence of atrophic gland (arrow) (original magnification, $\times 93$ ). I, A group of mast cells is present in stroma (original magnification, $\times 93$ ). (J-L) VP of a 19-month-old male Noble rat. J, Epithelia of most acini are atrophic (arrows) and exhibit cellular atypia (arrowheads). Note the presence of numerous corpora amylacea (blue arrows) in lumen (original magnification, $\times 12.5)$. K, High magnification of a region outlined (black lines) in J demonstrates cellular atypia with numerous vacuoles. In this region, some epithelial cells indicate loss of polarity (arrows) (original magnification, $\times 93$ ). L, High magnification of another region outlined (green lines) in J shows the vacuolized epithelium and numerous corpora amylacea in lumens (blue arrows) (original magnification, $\times 93$ ).

the sensitivity of a microarray by providing more dependable signals for low-abundance transcripts.

We used four separate microarray analyses to compare VP transcription profiles in four young ( 3 months old) and four aged (16 months old) rats (Fig. 2A). As represented by the scatterplot in Figure 2A, the Pearson correlation coefficient $r$ for the mean intensity values of the four comparisons of VP gene expression profiles in the two age groups was 0.9033. This indicated that, in NBL rats, the majority of VP genes showed no change in their expression levels with advancing age. Importantly, the scatterplots for these comparisons appear linear with no evidence of the curvature that usually indicates differences in the 
A.

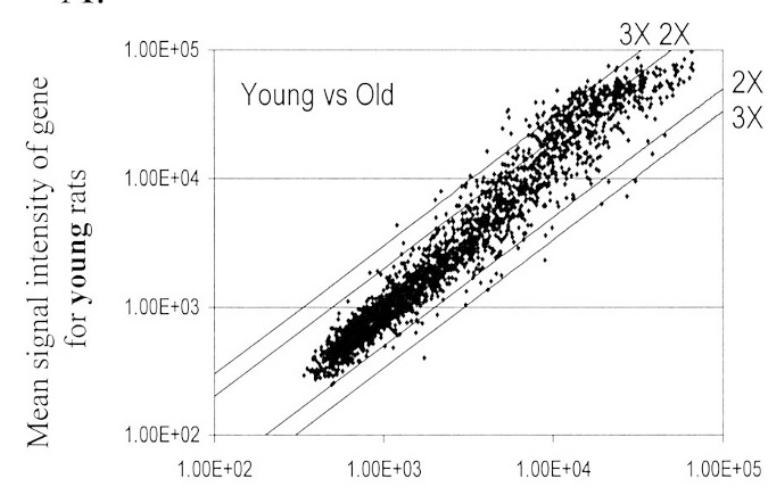

Mean signal intensity of gene for old rats

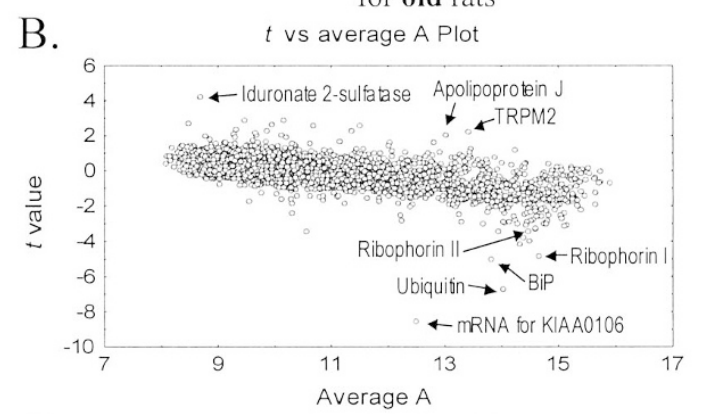

C.

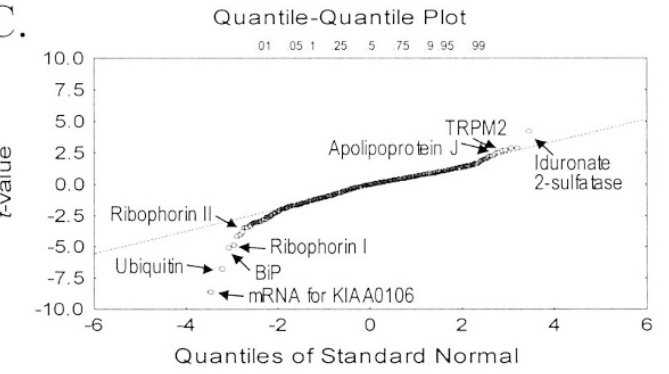

Figure 2.

Identification, using $t$-statistics, of differentially expressed genes between VPs of young and old rats. A, Scatterplot of CDNA microarray analysis. Total RNA samples from VPs of four young and four old rats were subjected to CDNA microarray analysis. The mean values of each gene for four samples from the old rats and those of four samples from the young rats were presented in the scatterplot. The Pearson correlation coefficient $r$ for the mean values of VP gene expression levels in the two age groups is 0.9033 . The lines represent the boundaries for a 2 -fold or 3-fold decrease (left) and a 2-fold or 3-fold increase (right) in old rats. B, Plot of $t$-statistic versus the average of overall intensity of each gene. The mathematical calculation for $t$-statistic of each gene was described in "Materials and Methods." The average overall intensity of each gene denotes the logarithm at base 2 for the square root of the multiple values of mean signals of Cy3 and Cy5 of each gene. $\mathrm{C}$, Normal quantile-quantile plot of $t$-statistics of all genes. The ranked $t$ statistics were plotted against the corresponding quantiles of the standard normal distribution. Genes of interest (arrows) with absolute value of $t$-statistics $>2$ and $p<0.05$ in comparisons between old and young rats.

amount of dye incorporated and the intensity signal with different cDNA abundances (Tseng et al, 2001). Collectively, these observations justified our use of the global median-intensity normalization for normalization of the intensity signal (Karsten et al, 2002; Tseng et al, 2001; Yang et al, 2002). To determine whether a gene is differentially expressed with statistical significance, we used $t$-statistics to analyze the microarray data according to Callow et al (2000). The difference between the mean intensity values of two groups and the variations among the samples within the same group were taken into consideration in the calculation of the $t$-score for each gene. We then plotted the $t$-values of all genes versus their average A values, which were logarithms at base 2 for the square root of mean signals of Cy 3 and Cy 5 (Fig. 2B). This $t$-score versus average $A$ plot was used to establish that genes with high $t$-scores were not because of their high expression levels (the A value). In other words, genes with low expression levels could still be identified as differentially expressed in this study. A quantile-quantile $(\mathrm{Q}-\mathrm{Q})$ plot was then used to visually identify genes with unusual $t$-scores (Fig. 2C). Genes located outside the 0.01 and 0.99 boundaries and that deviated from the straight line were recognized as having unusual $t$-statistics scores. In addition, the $p$-value for each gene was calculated to determine if differential expression of a gene was caused by aging and not by random or systematic variations. Genes with an absolute $t$-score $>2.0$ (outside the 0.01 and 0.99 boundaries) and a $p$-value $<0.05$ were considered differentially expressed. On the basis of these criteria, 78 of 1882 genes were identified as differentially expressed genes, 13 were overexpressed (Table 1), and 65 were underexpressed (Table 2) in the aged animals compared with levels found in young rats.

One major challenge facing cDNA microarray studies resides in the appropriate usage of algorithms in analyzing results. Many published microarray studies used an arbitrary selection criterion for identifying differentially expressed genes, such as 2- or 3-fold, up- or downregulation as cutoffs (Lee et al, 2001). The major drawback of this approach is that genes with changes in expression levels of $<200 \%$ to $300 \%$ are not recognized as differentially expressed. Thus, the approach presents a biased focus on genes with a high degree of differential expression and misses those that show consistent but a smaller degree of change. Many molecular changes associated with a cellular response or a physiologic state may involve less dramatic but consistent changes in gene-expression levels.

Several recently published studies have used pairwise comparisons to set the cutoff fold changes (Cao et al, 2001; Pang et al, 2002). This statistical method provides some statistic power but still has limitations, because it does not take into consideration the variations among the replicates in the identification of differentially expressed genes. The $t$-statistic used in this study represents a more robust algorithm and has recently been used by Callow and colleagues (2000) to identify hepatic genes that are differentially expressed among apolipoprotein Al knockout mice, scavenger receptor BI transgenic mice, and control mice. This statistical analysis overcomes the limitation on individual ani$\mathrm{mal} /$ hybridization variations and is well suited for use as the algorithm tool for this study.

\section{Genes Whose Expression Increased with Age}

Of the 78 VP genes we determined to be differentially expressed in young and old animals, only $13(17 \%)$ 
Table 1. Genes Up-regulated in VPs of Old Rats

\begin{tabular}{lcccc}
\hline \multicolumn{1}{c}{ Gene name } & $\begin{array}{c}\text { GeneBank } \\
\text { accession no. }\end{array}$ & $\begin{array}{c}\text { Relative } \\
\text { expression }\end{array}$ & $t$-value & $p$-value \\
\hline TRPM-2 & M64722 & 3.8 & 2.2 & 0.021 \\
Apolipoprotein J & J02908 & 3.0 & 2.0 & 0.008 \\
mRNA for 80K-L protein & D10522 & 2.8 & 2.2 & 0.036 \\
mRNA for BCL9 gene & Y13620 & 1.8 & 2.0 & 0.015 \\
mRNA of X-CGD gene involved in chronic & X04011 & 1.8 & 2.0 & 0.049 \\
$\quad$ granulomatous disease located on & & & & \\
$\quad$ chromosome X & X59405 & 1.6 & 2.7 & 0.023 \\
mRNA for membrane cofactor protein & D87447 & 1.6 & 2.0 & 0.022 \\
mRNA for KIAA0258 gene & M58342 & 1.4 & 4.2 & 0.005 \\
Iduronate 2-sulfatase & AB002349 & 1.4 & 2.5 & 0.020 \\
mRNA for KIAA0351 gene & M94151 & 1.4 & 2.1 & 0.011 \\
Cadherin-associated protein-related & X58536 & 1.3 & 2.9 & 0.042 \\
mRNA for HLA class I locus C heavy chain & X15892 & 1.3 & 2.8 & 0.004 \\
hcerN3 gene mRNA for N snRNP associated protein & D64159 & 1.3 & 2.6 & 0.014 \\
mRNA for 3-7 gene product & & & &
\end{tabular}

showed increased expression with age (Table 1). Among the up-regulated genes were iduronate 2-sulfatase (40\% increase), HLA class I locus $C$ heavy chain (30\% increase), membrane cofactor protein of the complement system (60\% increase), TRPM-2 (280\% increase), and apolipoprotein $J(200 \%$ increase). Although the increases for some of these genes were not dramatic, the $t$ - and $p$-values demonstrated that the increases were consistently statistically significant for all four comparisons. The purported functions of these genes seem to be related to some of the histopathologic changes that occur in the aging rat VP. For example, iduronate 2-sulfatase is a lysosomal enzyme (Froissart et al, 1995) that plays a major role in the breakdown of glycosaminoglycans, particularly heparan sulfate and dermatan sulfate, in the extracellular matrix (Freeman and Hopwood, 1992). An increase in iduronate 2-sulfatase expression in the VPs of aged rats may be related to a faster degradation of extracellular matrix mucopolysaccharides, possibly connected to prostatic atrophy in the senescent rats. Similarly, enhanced expression of HLA class I locus $C$ heavy chain may be associated with a heightened rate of cell death requiring faster presentation of intracellular peptides to the cell surface via the major histocompatibility complex mechanism for macrophage recognition and cell removal.

Up-regulation of the gene encoding TRPM-2 and the apolipoprotein $\mathrm{J}$ gene were detected by our array analyses. These two genes encode the same protein, clusterin (de Silva et al, 1990), which has been proposed to serve as a survival factor in prostateepithelial cells (July et al, 2002). Using semiquantitative RT-PCR analyses, we confirmed a progressive increase in expression of TRPM-2 in VPs of rats between 3 and 19 months of age (Fig. 3A). The levels of TRPM-2 in the VPs of young NBL rats (3-6 months old) were low and increased by 1.5-fold in the VPs of 9 -month-old animals $(p<0.05)$. The highest level of TRPM-2 (2-fold increase, $p<0.05)$ was found in animals 16 months of age or older. Our data are in accordance with previous reports (Bettuzzi et al, 1994; Marinelli et al, 1994) demonstrating increased TRPM-2 expression in the VPs of old Sprague-Dawley rats compared with that in young animals. Furthermore, our data support the notion that clusterin is a survival factor, because it is expressed at high levels in cuboidal epithelial cells of the VPs after castration (Marinelli et al, 1994). Expression of the gene encoding membrane cofactor protein of the complement system (MPC or CD46) (Post et al, 1991) also is increased in the VPs of old rats. MPC/CD46 is the most recently discovered C3b/C4b-binding cell surface glycoprotein that acts as an inhibitor of complement activation on host cells (Liszewski et al, 1991; Post et al, 1991). Its enhanced expression in the aged VP may protect prostatic cells against complement-mediated injury initiated by $\mathrm{C} 3 \mathrm{~b} / \mathrm{C} 4 \mathrm{~b}$ receptor-positive phagocytic cells (Schreiber, 1984), often observed in the aged VP.

Transcripts of three other known genes, X-CGD (80\% increase), 3-7 gene product (40\% increase), and BCL-9 (80\% increase), were found to be expressed at higher levels in the VPs of aged rats. The X-CGD is normally expressed in phagocytic cells such as macrophages and is responsible for releasing reactive oxygen species (Forman and Torres, 2001), whereas both 3-7 (Shiosaka and Saunders, 1982) and BCL-9 (Willis et al, 1998) are oncogenic molecules associated with leukemia. Expression of these genes in the aged VP may reflect increased infiltration of phagocytotic cells and lymphocytes into the prostates of older rats (>16 months old) (Fig. 1).

\section{Genes Whose Expression Decreased with Age}

Sixty-five (83\%) of 78 differentially expressed VP genes were found to be underexpressed in older rats compared with levels in young animals (Table 2). Remarkably, the genes could be classified into clusters with distinct cellular/biologic functions (Table 3).

Among the underexpressed genes, the largest group was represented by 27 genes that have known 


\begin{tabular}{|c|c|c|c|c|}
\hline Gene name & $\begin{array}{c}\text { GeneBank } \\
\text { accession no. }\end{array}$ & $\begin{array}{l}\text { Relative } \\
\text { expression }\end{array}$ & $t$-value & $p$-value \\
\hline mRNA for prolyl 4-hydroxylase beta subunit & X05130 & 6.2 & -2.5 & 0.034 \\
\hline Asparagine synthetase & M27396 & 4.8 & -2.9 & 0.026 \\
\hline High-density lipoprotein binding protein & M64098 & 4.4 & -3.0 & 0.021 \\
\hline mRNA for N-acetylglucosamide-(beta 1-4)-galactosyltransferase & X13223 & 3.6 & -2.4 & 0.025 \\
\hline mRNA for ribophorin I & Y00281 & 3.5 & -4.9 & 0.005 \\
\hline Actin depolymerizing factor & S65738 & 3.5 & -3.1 & 0.013 \\
\hline mRNA for KIAA0108 gene & D14696 & 3.5 & -2.3 & 0.024 \\
\hline mRNA for transmembrane protein rnp24 & X92098 & 3.4 & -4.0 & 0.007 \\
\hline mRNA for ribophorin $\|^{a}$ & Y00282 & 3.4 & -3.5 & 0.010 \\
\hline mRNA for Na,K-ATPase alpha-subunit & X04297 & 3.4 & -3.0 & 0.019 \\
\hline mRNA for transmembrane protein Tmp21-I & X97442 & 3.2 & -3.3 & 0.012 \\
\hline TRAF family member-associated NF-kB activator TANK & U63830 & 3.2 & -2.5 & 0.028 \\
\hline Spermidine synthase ${ }^{a}$ & M34338 & 3.2 & -2.2 & 0.030 \\
\hline Autoantigen calreticulin ${ }^{a}$ & M84739 & 3.1 & -2.8 & 0.037 \\
\hline mRNA for F1 beta subunit & D00022 & 3.0 & -3.1 & 0.009 \\
\hline ADP-ribosylation factor $1^{a}$ & M36340 & 3.0 & -2.4 & 0.016 \\
\hline ARL1 & L28997 & 3.0 & -2.3 & 0.022 \\
\hline Arg/Abl-interacting protein ArgBP2a & AF049884 & 3.0 & -2.1 & 0.031 \\
\hline mRNA for BiP protein & X87949 & 2.9 & -5.1 & 0.012 \\
\hline tra1 mRNA for homologue of murine tumor rejection antigen gp $96^{a}$ & X15187 & 2.9 & -3.1 & 0.032 \\
\hline Threonyl-tRNA synthetase & P26639 & 2.9 & -2.6 & 0.023 \\
\hline Phospholipase A2 & M86400 & 2.9 & -2.4 & 0.018 \\
\hline TEGT gene & $X 75861$ & 2.8 & -2.2 & 0.041 \\
\hline mRNA for KIAA0034 gene & $\mathrm{D} 21260$ & 2.8 & -2.0 & 0.004 \\
\hline Cytovillin 2 & J05021 & 2.7 & -3.2 & 0.008 \\
\hline mRNA for S-adenosylmethionine synthetase & X68836 & 2.7 & -2.6 & 0.024 \\
\hline mRNA for antizyme inhibitor & D88674 & 2.7 & -2.2 & 0.021 \\
\hline Calnexin & M94859 & 2.7 & -2.1 & 0.038 \\
\hline Neuroleukin & K03515 & 2.6 & -2.8 & 0.010 \\
\hline mRNA for glutaminyl-tRNA synthetase & X54326 & 2.6 & -2.1 & 0.031 \\
\hline rab2 mRNA, YPT1-related and member of ras family & X12953 & 2.6 & -2.0 & 0.014 \\
\hline mRNA for protein phosphatase $2 A$ [beta-type] & $\mathrm{X} 12656$ & 2.5 & -2.7 & 0.011 \\
\hline Ubiquitin & M26880 & 2.4 & -6.8 & 0.006 \\
\hline mRNA for vascular smooth muscle alpha-actin & X13839 & 2.4 & -3.1 & 0.038 \\
\hline Brain-type clathrin light-chain b & M20469 & 2.3 & -2.4 & 0.024 \\
\hline mRNA for clathrin coat assembly protein-like & D63643 & 2.3 & -2.0 & 0.029 \\
\hline Aspartyl-tRNA synthetase alpha-2 subunit & J05032 & 2.2 & -3.4 & 0.003 \\
\hline mRNA for ezrin ${ }^{a}$ & $X 51521$ & 2.2 & -2.7 & 0.022 \\
\hline mRNA for ras-related GTP-binding protein ${ }^{a}$ & D78132 & 2.2 & -2.6 & 0.002 \\
\hline Spermidine aminopropyltransferase & AD001528 & 2.2 & -2.0 & 0.048 \\
\hline mRNA for proteasome subunit HC2 & D00759 & 2.2 & -2.0 & 0.018 \\
\hline Elongation factor 1 -alpha 1 [PTI-1] & L41490 & 2.1 & -4.2 & 0.023 \\
\hline Subtilisin-like protease PC8 precursor & U40623 & 2.1 & -2.6 & 0.023 \\
\hline Putative NDP kinase [nm23-H2S] & M36981 & 2.1 & -2.5 & 0.004 \\
\hline 14-3-3 protein epsilon isoform & U43399 & 2.1 & -2.3 & 0.001 \\
\hline Protein phosphatase $2 \mathrm{~A}$ regulatory subunit alpha-isotype [alpha-PR65] & J02902 & 2.1 & -2.0 & 0.043 \\
\hline PR264 mRNA & $\mathrm{X} 62447$ & 2.1 & -2.0 & 0.014 \\
\hline Signal-transducing guanine nucleotide-binding regulatory $(G)$ protein beta subunit & M16538 & 2.0 & -3.8 & 0.021 \\
\hline mRNA for eukaryotic initiation factor 4Al1 & D30655 & 2.0 & -2.3 & 0.039 \\
\hline Transmembrane secretory component & S62403 & 2.0 & -2.2 & 0.019 \\
\hline Protein tyrosine kinase & U02680 & 1.9 & -2.9 & 0.030 \\
\hline mRNA for KIAA0106 gene & D14662 & 1.8 & -8.6 & 0.002 \\
\hline mRNA for ribosomal protein L3 & X73460 & 1.8 & -3.2 & 0.006 \\
\hline Alpha NAC mRNA & X80909 & 1.8 & -2.6 & 0.000 \\
\hline mRNA for yeast methionyl-tRNA synthetase homologue & X94754 & 1.8 & -2.5 & 0.012 \\
\hline Translation initiation factor elF3 p66 subunit & U54558 & 1.8 & -2.1 & 0.034 \\
\hline mRNA for gamma-aminobutyric-acid receptor alpha-subunit & $\mathrm{X} 13584$ & 1.7 & -3.1 & 0.022 \\
\hline Alpha-tubulin & K00558 & 1.7 & -2.9 & 0.039 \\
\hline hVps41p & U87309 & 1.7 & -2.0 & 0.040 \\
\hline SSR2 mRNA for beta-signal sequence receptor & D37991 & 1.6 & -3.5 & 0.011 \\
\hline $\operatorname{NAD}(\mathrm{H})$-specific isocitrate dehydrogenase alpha subunit precursor & U07681 & 1.6 & -2.9 & 0.009 \\
\hline Small acidic protein & U51678 & 1.6 & -2.0 & 0.046 \\
\hline Ferritin $\mathrm{H}$ chain & L20941 & 1.6 & -2.0 & 0.008 \\
\hline mRNA for transient axonal glycoprotein & X67734 & 1.5 & -3.5 & 0.002 \\
\hline Channel-like integral membrane protein & U41517 & 1.4 & -2.0 & 0.014 \\
\hline
\end{tabular}

\footnotetext{
${ }^{a}$ Known androgen-inducible gene shown in other studies.
} 


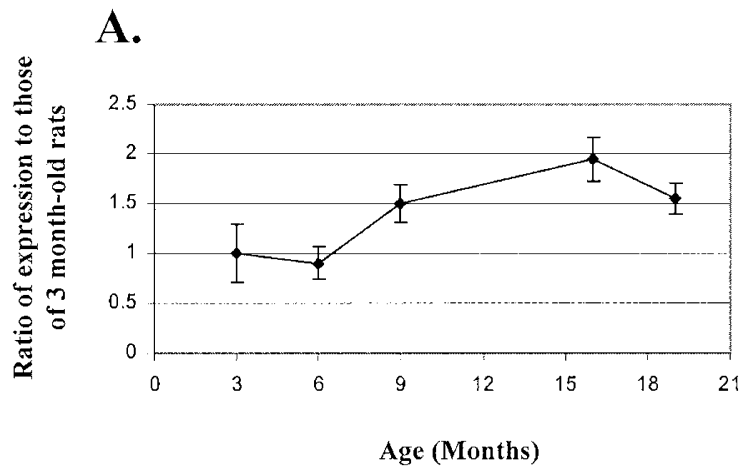

B.

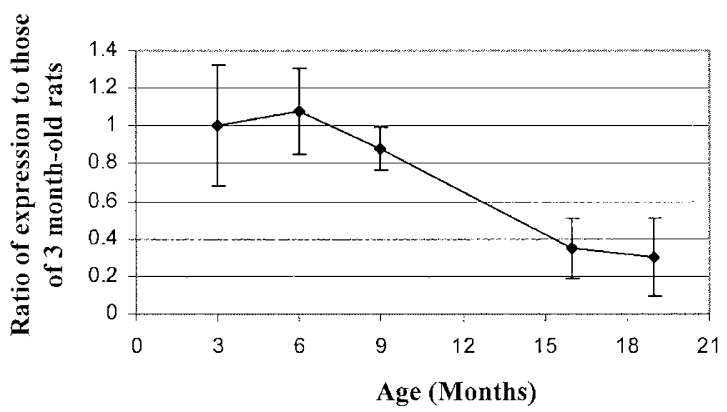

C.

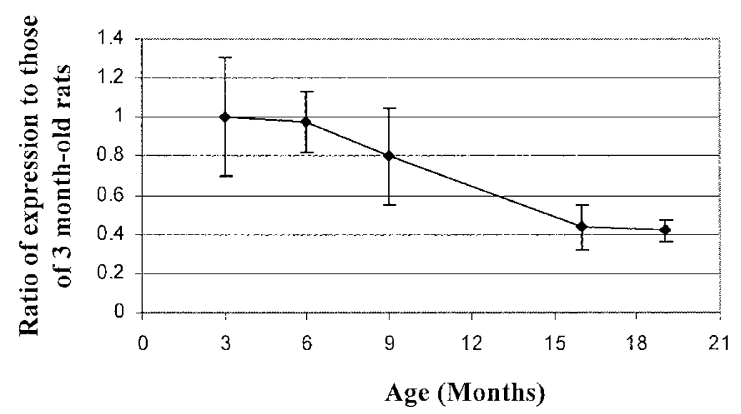

Figure 3.

Post hoc semiquantitative RT-PCR analyses of TRPM2 (A), ribophorin II (B), and rat $\mathrm{BiP}(\mathrm{C})$ on the ventral prostates of 3-, 6-, 9-, 16-, and 19-month-old rats. Total RNA was isolated and subjected to semiquantitative RT-PCR. The mean values of the expression levels of TRPM2, ribophorin II, and rat BiP relative to that of $\beta$-actin in different ages of rats were presented. Standard deviations (bars) for different animals in each age group in three separate experiments.

functions associated with protein synthesis, secretion, turnover, or degradation, or that are in cellular organelles involved in the regulation of these processes.

Although slowing down of protein synthesis is widely believed to be a common change associated with cellular aging (Rattan, 1991), the phenomenon has not been demonstrated in the prostate. We detected an aging-related decrease in the expression of four genes encoding amino acyl-tRNA synthetases (threonyl-tRNA synthetase, glutaminyl-tRNA synthetase, aspartyl-tRNA synthetase, and methionyltRNA synthetase). These enzymes are involved in the aminoacylation of tRNA during protein synthesis (lbba and Soll, 2000). Functionally, they are pivotal in determining how the genetic code is interpreted as amino acids. Significant reduction in their expression may compromise the overall fidelity of protein synthesis.
The aged VP also contains lower levels of transcripts of three genes encoding enzymes (prolyl-4hydroxylase beta subunit, asparagine synthetase, and S-adenosylmethionine synthetase) required in proline, aspartate, and methionine metabolism. A reduction in amino acid metabolism often affects protein synthesis in a global manner. Additionally, transcription of genes encoding proteins in the initiation of translation, such as eukaryotic initiation factor 4All and translational initiation factor elF3 p66 subunit, were decreased 2-fold in the VPs of old rats. The eukaryotic initiation factor 4All is a member of protein-synthesis initiation factors that are needed for binding mRNA to the ribosome (Sudo et al, 1995). It forms a complex with elF4F, elF4G, elF4E, and elF4A to regulate translation of messenger RNAs and selectively interacts with the $40 S$ ribosomal subunit of the protein synthetic machinery (Jackson and Wickens, 1997). Another agedependent down-regulated gene detected in our array analyses is L-3 ribosomal protein. It is part of the protein synthesis machinery and is a ribosomal assembly initiator for the $50 \mathrm{~S}$ assembly and mediates binding of mRNA to the ribosome (Nowotny and Nierhaus, 1982).

The elongation factor 1 alpha $(\mathrm{EF}-1 \alpha)$ gene also was down-regulated in the aged VP. During protein synthesis, the EF- $1 \alpha$ protein acts as a nucleotide exchange protein and binds to GTP and aminoacyltRNA, resulting in their codon-dependent placement at the acceptor site of the ribosome (Riis et al, 1990). It provides protein translation fidelity and is a pivotal regulator of rates of protein synthesis (Merrick, 1992). A decline in EF-1 $\alpha$ mRNA in the VPs of old rats may lead to loss of proofreading during peptide chain elongation in protein synthesis and may contribute to cellular transformation in an epigenetic manner. It has been reported that expression of a truncated EF- $1 \alpha$, which has no GTP binding domain, is associated with prostate cancer (Shen et al, 1995).

An interesting functional cluster of down-regulated genes consists of six that encode the rough endoplasmic reticulum (ER)-associated proteins ribophorin I and II, BiP protein, calnexin, calreticulin, and $\beta$-signal sequence receptor. We confirmed declines in expression of ribophorin II and $\mathrm{BiP}$ in the VPs of old rats by post hoc analysis. Ribophorin II mRNA in the VP showed high levels of expression in 3-, 6- and 9-month-old animals and decreased in aged rats (16 and 19 months old, a reduction of $\sim 3$-fold, $p<0.05$ ) (Fig. 3B). The pattern of VP expression of BiP mRNA among different age groups of rats was similar to that of ribophorin II, showing significant down-regulation in the 16- and 19-month-old animals ( 2.5 -fold compared with expression in 3-month-old rats, $p<0.05$ ) (Fig. 3C).

These ER-associated proteins are known to function in posttranslational modification of proteins and maintenance of protein fidelity. Ribophorins I and II, located in the rough ER, form a complex with oligosaccharyltransferase that affects the cotranslational $\mathrm{N}$-glycosylation of newly synthesized polypeptide (Fu et al, 2000). Meanwhile, BiP (GRP78), a member of the 
Table 3. Under-expressed Genes in the VPs of Aged Rats Classified Based on Their Presumed Cellular Functions

A. Genes associated with protein synthesis, transport, turnover, and degradation, and those encoding components of the protein synthetic

\begin{tabular}{|c|c|}
\hline \multicolumn{2}{|l|}{ Protein synthetic machinery } \\
\hline \multicolumn{2}{|l|}{ Amino acyl-tRNA synthetases } \\
\hline Threonyl-tRNA synthetase & $\downarrow 2.9 X$ \\
\hline Glutaminyl-tRNA synthetase & $\downarrow 2.6 X$ \\
\hline Aspartyl-tRNA synthetase & $2.2 \mathrm{X}$ \\
\hline Methionyl-tRNA synthetase & $1.8 \mathrm{X}$ \\
\hline Eukaryotic initiation factor 4 All & $2.0 \mathrm{X}$ \\
\hline Translational initiation factor elF3 p66 subunit & $1.8 \mathrm{X}$ \\
\hline Ribosomal protein L3 & $1.8 \mathrm{X}$ \\
\hline Elongation factor 1 alpha & $\downarrow 2.1 \mathrm{X}$ \\
\hline \multicolumn{2}{|l|}{ Endoplasmic reticulum proteins involved in protein modification, trafficking and fidelity } \\
\hline Ribophorin I & $\downarrow 3.5 X$ \\
\hline Ribophorin II & $\downarrow 3.4 \mathrm{X}$ \\
\hline BiP protein & $2.9 \mathrm{X}$ \\
\hline Autoantigen calreticulin & $3.1 \mathrm{X}$ \\
\hline Calnexin & $2.7 \mathrm{X}$ \\
\hline Beta-signal sequence receptor (SSR2) & $\downarrow 1.6 \mathrm{X}$ \\
\hline \multicolumn{2}{|l|}{ Proteins in vesicle formation, and protein/membrane transport and trafficking } \\
\hline Brain-type clathrin-light chain b & $\downarrow 2.3 \mathrm{X}$ \\
\hline Clathrin-coat assembly protein-like & $2.3 \mathrm{X}$ \\
\hline Ras-related GTP-binding protein (Rab) & $2.2 \mathrm{X}$ \\
\hline Rab2 & $2.6 \mathrm{X}$ \\
\hline ADP-ribosylation factor 1 (ARF-1) & $3.0 \mathrm{X}$ \\
\hline ADP-ribosylation factor-like protein (ARL1) & $3.0 \mathrm{X}$ \\
\hline $14-3-3$ protein epsilon isoform & $\downarrow 2.1 X$ \\
\hline hVps41p & $\downarrow 1.7 \mathrm{X}$ \\
\hline \multicolumn{2}{|l|}{ Protein degradation } \\
\hline Ubiquitin & $\downarrow 2.4 \mathrm{X}$ \\
\hline Proteasome subunit HC2 & $\downarrow 2.2 X$ \\
\hline Amino acid metabolisms & \\
\hline Prolyl 4-hydroxylase beta subunit & $\downarrow 6.2 X$ \\
\hline Asparagine synthetase & $4.8 \mathrm{X}$ \\
\hline S-adenosylmethionine synthetase & $\downarrow 2.7 X$ \\
\hline \multicolumn{2}{|l|}{ B. Heat shock protein } \\
\hline BiP protein & $\downarrow 2.9 X$ \\
\hline \multirow{2}{*}{\multicolumn{2}{|c|}{ C. Genes regulating spermidine and spermine synthesis, conversion and degradation }} \\
\hline & \\
\hline Spermidine synthase & $\downarrow 3.2 X$ \\
\hline Spermidine aminopropyltransferase & $2.2 \mathrm{X}$ \\
\hline Antizyme inhibitor & $2.7 \mathrm{X}$ \\
\hline S-adenosylmethionine synthetase & $\downarrow 2.7 X$ \\
\hline \multicolumn{2}{|l|}{ D. Cytoskeleton organization protein } \\
\hline Actin depolymerization factor & $\downarrow 3.5 X$ \\
\hline Elongation factor 1 alpha & $\downarrow 2.1 \mathrm{X}$ \\
\hline Alpha-tubulin & $\downarrow 1.7 \mathrm{X}$ \\
\hline Vascular smooth muscle alpha-actin & $\downarrow 2.4 X$ \\
\hline Microvillus associated proteins & \\
\hline Cytovillin-2 & $\downarrow 2.7 X$ \\
\hline Ezrin & $\downarrow 2.2 X$ \\
\hline \multicolumn{2}{|l|}{ E. Energetic metabolism } \\
\hline \multicolumn{2}{|l|}{ Galactose metabolism } \\
\hline $\mathrm{N}$-acetylglucosamide-(beta 1,4)-galactosyltransferase & $\downarrow 3.6 \mathrm{X}$ \\
\hline Pentose phosphate cycle/starch and sucrose metabolism & \\
\hline Neuroleukin & $\downarrow 2.6 \mathrm{X}$ \\
\hline Oxidative phosphorylation & \\
\hline F1 beta subunit & $\downarrow 3.0 \mathrm{X}$ \\
\hline Na,K-ATPase alpha subunit & $\downarrow 3.4 \mathrm{X}$ \\
\hline Citrate/isocitrate oxidation & \\
\hline $\operatorname{NAD}(\mathrm{H})$-specific isocitrate dehydrogenase alpha subunit precursor & $\downarrow 1.6 \mathrm{X}$ \\
\hline \multicolumn{2}{|l|}{ F. Signal transduction pathways } \\
\hline \multicolumn{2}{|l|}{ Protein phosphatase $2 A$} \\
\hline Protein phosphatase $2 \mathrm{~A}$ beta type & $\downarrow 2.5 \mathrm{X}$ \\
\hline Protein phosphatase $2 A$ regulatory subunit alpha-Rab2 & $2.1 \mathrm{X}$ \\
\hline Rab2 & $2.6 \mathrm{X}$ \\
\hline Ras-related GTP-binding protein & $2.2 \mathrm{X}$ \\
\hline Putative NDP kinase & $2.1 \mathrm{X}$ \\
\hline Signal-transducing guanine nucleotide-binding regulatory $(G)$ protein beta subunit & $2.0 \mathrm{X}$ \\
\hline Protein tyrosine kinase & $\downarrow 1.9 \mathrm{x}$ \\
\hline Transmembrane protein mp24 & $\downarrow 3.4 \mathrm{X}$ \\
\hline
\end{tabular}


hsp70 family of chaperones, is one of the most abundant proteins in the ER lumen. BiP has been implicated in cotranslational folding of nascent polypeptides and in the recognition and disposal of aberrant polypeptides (Hatano et al, 1997; Hellman et al, 1999). Interestingly, calnexin and calreticulin, two closely related molecular chaperones in rough $\mathrm{ER}$, when associated with $\mathrm{BiP}$, suppress aggregation and promote refolding of protein and glycoprotein substrates (Stronge et al, 2001). Together, these three ER molecular chaperones play essential roles in the correct protein folding, assembly, and glycosylation of secreted proteins (Buchner, 1996). In agreement with our finding, BiP transcription was found to decline in hepatocytes isolated from old rats compared with that in young rats (Heydari et al, 1995). Importantly, expression of calreticulin was shown to be regulated by androgen in rat prostatic epithelial cells (Zhu et al, 1998). In this regard, diminished expression of calnexin and calreticulin in aged VP could be the result of an age-dependent decline in serum testosterone levels. Finally, $\beta$-signal sequence receptor (SSR2), which encodes an ER membrane protein associated with protein translocation across the ER membrane, also has been identified to be modestly down-regulated in the aged VP (Chinen et al, 1995).

Vesicle transport and protein/membrane trafficking play major roles in trans-Golgi network function, lysosome biogenesis, endocytosis, and protein secretion. Our array analyses revealed a lower expression in the aged rats of a set of seven genes encoding proteins involved in vesicle coat formation (brain-type clathrin light chain $b$ and clathrin-coat assembly protein-like) (Brodsky et al, 2001; Schmid, 1997), vesicle trafficking, and vesicle-mediated transport [Ras-related GTPbinding protein (Rab), Rab2, ADP-ribosylation factor-1 (ARF-1), ARF-like protein (ARL), and 14-3-3 protein epsilon] (Gu et al, 2001; Takei and Haucke, 2001). Clathrins, via interaction with adaptor complexes, are recruited to the cell membrane or to the trans-Golgi network, where they assemble into a lattice coat on vesicles (Grodsky et al, 1982; Schmid, 1997). Rabs, found at the plasma membrane and on organelles mediating secretion and endocytosis, regulate vesicle transport, docking, and fusion (Mullins and Bonifacino, 2001). Meanwhile, different members of ADPribosyltransferase factors (ARFs) and ARLs are found in various intracellular membranes in a cell/tissuespecific manner. They have specific and shared functions in controlling vesicular transport, membrane trafficking, Golgi functions, and apoptosis (Serafini et al, 1991; Van Valkenburgh et al, 2001). The 14-3-3 proteins are abundant acidic proteins with numerous isoforms and diverse functions. Some of them, including 14-3-3 epsilon, are thought to act primarily on the actin cytoskeleton to regulate vesicle targeting, trafficking, and exocytosis (Roth et al, 1999). They also are implicated in Ras signaling pathways (Gelperin et al, 1995). Collectively, down-regulation of this set of genes in the aged VP will affect turnover of normal cellular proteins, disposal of abnormal proteins, internalization of cell-surface receptors, autophagy, re- lease of exocytosed nutrients, inactivation of pathogens, and antigen processing (Brodsky et al, 2001; Gu et al, 2001; Schmid, 1997; Takei and Haucke, 2001). Little is known about the relationship between functional roles of these genes and prostatic function, except for a single report showing androgen regulation of clathrin light chains in LNCaP cells (Prescott and Tindall, 1998). Prostatic epithelium in young rats is a highly secretory tissue, and exocytosis is a pivotal mechanism of protein export. In contrast, secretion and exocytosis decline in the aged VP. It remains to be determined if declining levels of testosterone in circulation are responsible for underexpression of these genes in the aged VP.

The alkaline phosphatase (ALP) pathway, another protein transport system operating in the prostate, transports proteins to the vacuole. It requires a homooligomeric form of Vps41p for the formation of ALPcontaining vesicles at the Golgi complex via interactions with the AP-3 adaptor complex (Darsow et al, 2001). In the aged VP, we detected a moderate reduction in the expression of Vps41p. However, a previous study reported increased prostatic ALP activity, but not prostatic acidic phosphatase activity, in aged rats (Hinkle, 1988). Hence, further studies are needed to reconcile this apparent paradox between Vps41p underexpression and ALP up-regulation in the VP of senescent rats.

We found age-dependent loss of expression of two VP genes (ubiquitin and proteasome subunit HC2) whose protein products are pivotal to protein degradation. Proteasome subunit HC2 is a component of the $20 \mathrm{~S}$ proteasome protein degradation system, and ubiquitin is a constituent of the ubiquitin-26S proteasome system. The major cellular defense mechanism against the deleterious effects of oxidized proteins is afforded by the $20 \mathrm{~S}$ proteasome, which specifically recognizes and removes oxidized proteins (Davies, 2001; Shringarpure et al, 2001). In contrast, the ubiquitin-26S proteasome plays a much smaller role in oxidized protein degradation but is pivotally involved in the degradation of cellular signaling proteins, including the various transcriptional factors. In agreement with our findings, declines in proteasome activity of human fibroblasts (Ly et al, 2000; Sitte et al, 2000a, 2000b), pulmonary arterial-endothelial cells (Merker et al, 2001), and gastrocnemius muscle of the mouse during senescence have been noted (Pang et al, 2002). Taken together, a reduction in expression of genes encoding key proteasomal proteins is apparently a common phenomenon in cellular aging. Reduced expression of these genes in the aged VP would dramatically affect its ability to remove oxidized protein and regulate signaling molecules.

During aging, the stress response and the production of heat-shock protein decrease, correlating with a decline in stress tolerance (Feder and Hofmann, 1999; Verbeke et al, 2000). Heat-shock proteins serve as sensors in the recognition of damaged proteins and perform repairs on moderately misfolded proteins, thereby preventing inter- or intramolecular aggregation (Feder and Hofmann, 1999; Verbeke et al, 2000). 
In the aged VP, we detected underexpression of two heat-shock protein genes, BiP (GRP78) and tra 1 (heat-shock protein gp96), suggesting a possible reduction in cytoprotection for prostatic cells in old rats.

Interestingly, four underexpressed genes in the aged VP are involved in spermidine and spermine synthesis (spermidine synthase, spermidine aminopropyltransferase, S-adenosylmethionine synthetase, and antizyme inhibitor). The prostate synthesizes and sequesters high levels of polyamines (putrescine, spermidine, and spermine) (WilliamsAshman and Canellakis, 1979), which are known to inhibit normal growth of the gland (Cohen et al, 2001; Pegg, 1986; Smith et al, 1995). Spermidine is synthesized from the precursor putrescine by the enzyme spermidine synthase. Putrescine, in turn, is formed from decarboxylation of ornithine via ornithine decarboxylase activity. Last, spermidine is converted to spermine via the catalytic action of spermidine aminopropyltransferase (or spermine synthase). Both conversions involve transfer of aminopropyl residues from decarboxylated S-adenosylmethionine (AdoMet). The level of AdoMet is regulated by the enzyme S-adenosylmethionine synthetase. As a negative feedback mechanism, antizyme, induced by the high level of polyamines, inhibits decarboxylation of ornithine by targeting ornithine decarboxylase for rapid degradation by the 26S proteasome (Heller et al, 1976; Murakami et al, 1992). Decreased expression of these polyamine metabolism genes undoubtedly will lead to reduced levels of spermidine/spermine and leave the aged VP unguarded against growth stimuli. Our findings corroborated with results from a previous study showing a decline in polyamine content and an increase in ornithine decarboxylase activity in VPs of aged rats (Bettuzzi et al, 1994). It is therefore not surprising to observe development of atypical hyperplasia or dysplasia amid diffuse atrophy in the VPs of senescent rats. Disturbance in this intricate mechanism for regulating growth stimulation and repression also may occur in the senescent human gland.

The cytoskeleton is an important regulator of cell shape, proliferation, and differentiation (Rao and Cohen, 1991). The actin-based cytoskeletal network, in particular, interacts with extracellular matrix proteins, cell surface membranes, second messengers, cytoplasmic enzymes, and the cell nucleus to regulate a wide spectrum of cellular functions. Virtually no information is available on how cytoskeleton function changes during aging of the prostate. In this study, our microarray data revealed lower expression of actin depolymerization factor, $\alpha$-tubulin, vascular smooth muscle $\alpha$-actin, and EF- $1 \alpha$ in the VPs of old rats. Diminished expression of cytoskeleton-associated genes in the prostate may be a result of an increased number of atrophic prostatic acini as rats advance in age. A dramatic reduction in epithelial cell height and cell volume may result in reorganization of cytoskeletal components. Nevertheless, altered expression of the cytoskeleton network should have broad implication for VP function during aging.
Transcripts of ezrin, also known as cytovillin, were underexpressed in the aged VP. Ezrin/cytovillin is a cytoplasmic protein enriched in microvilli and other cell-surface structures. It has been implicated as playing a membrane-cytoskeleton linker role (Turunen et al, 1994). Reduced expression of ezrin/cytovillin could be a result of the loss of tall columnar (secretory) cells in prostatic epithelia during the aging of rat VP.

Significant declines in the expression of genes related to energy metabolism were observed in the aged VP. These include those affecting galactose metabolism, pentose phosphate oxidation, oxidative phosphorylation, $\mathrm{Na} / \mathrm{K}-\mathrm{ATP}$ ase activity, and citrate/isocitrate utilization. $\mathrm{Na} / \mathrm{K}$-ATPase activity, localized on the cell membrane, regulates cell volume and consumes a significant amount of cellular energy (Kowluru et al, 1989). It has been shown to undergo age-related declines in other bodily organs (Lenaz et al, 2000). The F1 beta subunit of mitochondrial $\mathrm{H}(+)$-ATP synthase is a nucleus-encoded mitochondrial inner membrane protein with major involvement in oxidative phosphorylation (Weber and Senior, 1997). Isocitrate dehydrogenases (IDHs) are key mitochondrial enzymes facilitating the use of isocitrate or citrate for respiratory $\mathrm{O}_{2}$ consumption in the tricarboxylic acid cycle. NADPIDH and NAD-IDH in rat VP (Costello et al, 1976) and NADP-IDH in the prostates of bonnet monkeys (Arunakaran et al, 1992) were shown to be under androgen regulation. Collectively, declines in the expression of these genes reflect a lower metabolic state in the aged VP.

Finally, several signal transduction genes were found to be underexpressed in the VP of aged rats. They include members in the protein phosphatase $2 \mathrm{~A}$ pathway, ras-related GTP-binding protein, signaltransducing guanine nucleotide-binding regulatory $G$ protein beta subunit, and several kinases. Diminished expression in these genes is expected to drastically affect intracellular signaling in aged VP cells.

\section{General Discussion}

Androgen deficiency, also known as andropause, affects an estimated 1 in 200 aging men, and the condition is now commonly treated with testosteronereplacement therapy (Bain, 2001; Morales and Tenover, 2002; Morley and Perry III, 2000). Relevant to the issue of how andropause and/or testosteronereplacement therapy affect the human prostate, it is logical to ask whether changes in gene expression observed in the aging rat VP are primarily caused by a decline in androgen support with advancing age. Several genes, including ribophorin II, transmembrane protein Tmp21-1, spermidine synthase, calreticulin, ADP-ribosylation factor 1, antigen gp96, ezrin, and ras-related GTP-binding protein (Table 2), identified in this gene-profiling study are known to be regulated by androgen (Cyriac et al, 2002; Pang et al, 2002; Zhu et al, 1998). Thus, it is possible that some of the ageaffected changes in gene expression are caused by a decline in circulating androgen in old animals. In this regard, we expect that supplementation with testos- 
terone in aged rats would revert the expression levels of these androgen-regulated genes to "young control" levels. On the other hand, expression profiles of other genes may be intrinsic to the aging process. To delineate these two classes of genes, we have planned experiments involving testosterone supplementation in aged rats. Findings from these future studies should have important implications for male aging and prostate health (Morley and Perry III, 2000).

\section{Conclusion}

We have successfully used a moderate-density cDNA microarray to detect aging-related changes in gene profile in the rat VP. The findings are intriguing in a number of aspects. First, clusters of genes with related functions were found to be affected by aging in the rat VP. This finding demonstrates the effectiveness of microarray analyses in the rapid detection of a multitude of molecular changes associated with aging in this tissue. Second, transcriptional-profiling data are highly informative and for the first time suggest a widespread loss of functions in the senescent VP, affecting its ability to produce and synthesize proteins, check protein fidelity, and remove harmful modified proteins. This could be a major epigenetic cause of cellular dysregulation and transformation. Third, microarray data suggested a loss of cell-growth inhibition and a gain in anti-apoptotic potential. This imbalance could partially explain the aberrant morphologic changes observed in the aged VP. Last, the aged VP, in general, exhibits a decline in energy metabolism, reduced anabolism, and dysregulation of signal transduction pathways. Compared with the molecular/cellular changes in other bodily organs (Cao et al, 2001; Lee et al, 2000, 2001; Pang et al, 2002), some changes in the aged VP are unique, whereas others are common to all. Broadly speaking, if these changes occur in the human prostate, they could explain why the gland is susceptible to disease development in elderly men.

\section{Materials and Methods}

\section{Animals and Tissue Collection}

Male, NBL rats, 5 to 6 weeks old, were purchased from Charles River Breeding Laboratory (Wilmington, Massachusetts). The rats were housed at the animal care facility in University of Massachusetts Medical School and fed rat chow and water ad libitum until they reached the appropriate age. Twenty NBL rats divided into five groups of four were killed at 3, 6, 9, 16 , and 19 months of age. Animals were killed with an overdose of isoflurane (Ohmeda Caribe, New Jersey) anesthesia followed by decapitation. VPs were carefully excised from the prostate-urethra-bladder complex and cut in half. One half was formalin-fixed and paraffin-embedded for histologic studies. The other half was snap-frozen in liquid nitrogen and kept at $-70^{\circ} \mathrm{C}$ until RNA isolation. Protocols of animal usage were previously approved by the University of Massachusetts Medical School Animal Care and Usage Committee.

\section{RNA Isolation and RT-PCR}

Total RNA was isolated using TRI reagent (Sigma, St. Louis, Missouri) according to the manufacturer's protocol. RNA integrity was validated according to previously described protocols (Cyriac et al, 2002). Semiquantitative RT-PCR, conducted as previously described (Cyriac et al, 2002), was used in post hoc analyses to validate changes in the expression of selected genes during aging. One microgram of total RNA was reverse transcribed using GeneAmp RNA PCR kit (Perkin Elmer, Norwalk, Connecticut), and $2 \mu \mathrm{l}$ of the resulting cDNA was used in each PCR for $\beta$-actin, TRPM2, ribophorin II, and rat homolog of human BiP. Intron-spanning primers were used to prime first-strand cDNA synthesized from RNA samples isolated from VPs of the various age groups. The forward primer for ribophorin II is 5'-TGT TTT GTC TCA CGC TCT GG-3', and the reverse primer is 5'-CAG AGG ATG GGG TTC TTC AA-3'. The forward primer for BiP is AAG ACG GGC AAA GAT GTC AG-3' and the reverse primer is $5^{\prime}$-TTT GTC AGG GGT CTT TCA CC-3. The forward primer for TRPM2 is 5'-GGT GAA GAT GAC CCG ACA GT-3', and the reverse primer is 5'-TGT GAT GGG GTC AGA GTC AA-3'. The forward primer for $\beta$-actin is $5^{\prime}$-ATG GAT GAC GAT ATC GCT GCG-3', and the reverse primer is $5^{\prime}-\mathrm{CTC}$ CAT ATC GTC CCA GTT GG-3'. All PCR conditions were optimized for quantification of relative message contents under nonsaturating conditions. The PCR programs were 30 cycles for $\beta$-actin, 32 cycles for TRPM-2, and 35 cycles for ribophorin II and BiP of 1 minute at $94^{\circ} \mathrm{C}, 1$ minute at $60^{\circ} \mathrm{C}$ (except $57^{\circ} \mathrm{C}$ for $\beta$-actin), and 1 minute at $72^{\circ} \mathrm{C}$. The PCR products were subjected to electrophoresis in $2 \%$ agarose gel with ethidium bromide, and the fluorographs under ultraviolet irradiation were captured by Kodak DC290 digital camera (Eastman Kodak, Rochester, New York). The signals of PCR product were quantified using Kodak 1D Image Analysis software (Eastman Kodak). Levels of $\beta$-actin cDNA served as a loading control. Relative levels of mRNA for TRPM-2, ribophorin II, and BiP were calculated following normalization against the signal intensity for $\beta$-actin mRNA. The amplimer obtained from the primer set designed from human BiP on rat cDNA was DNA sequenced to demonstrate high homology between the amplimer and human BiP.

\section{cDNA Microarray Experiments}

The Micromax TSA labeling and detection kit (Perkin Elmer) was used according to the protocol provided by the manufacturer. The TSA-labeling protocol was chosen because it is a posthybridization amplification system that permits detection of differential transcript expression in samples with relatively small amounts of total RNA. Briefly, $2 \mu \mathrm{g}$ of total RNA from the VPs of young ( 3 months old) and old (16 months old) rats were subjected to cDNA synthesis using fluoresceinlabeled and biotinylated nucleotides, respectively. Equal quantities of two cDNA probes, derived from 
young and old animals, were mixed and hybridized on a cDNAs microarray slide in a Corning microarray hybridization chamber (Corning, Corning, New York) at $60^{\circ} \mathrm{C}$ overnight. The hybridized slide was washed under stringent conditions. The fluorescein-labeled probes on the slide were recognized by an antibody to fluorescein that was conjugated to horseradish peroxidase. The enzyme catalyzed the deposition of cyanine (Cy)3-labeled tyramide on the labeled cDNA. After inactivation of residual horseradish peroxidase from the first reaction, streptavidin-linked horseradish peroxidase was used to deposit cyanine 5 (Cy5) tyramide to the biotin-labeled cDNA probe on the slide. The slide was washed extensively and air-dried. The hybridized microarray slides were scanned using a ScanArray confocal laser scanner (GSI Lumonics, Watertown, California) at 10- $\mu \mathrm{m}$ pixel resolution for $\mathrm{Cy} 3$ and Cy5 signal detection. ImaGene analysis software (BioDiscovery, Los Angeles, California) was used to quantify Cy3 and Cy5 signals on each spot. For each spot, average intensity of all pixels within intensity values falling in the range of $50 \%$ to $95 \%$ of maximal intensity was calculated (the "signal intensity"). The "background signal" was calculated from average intensity of pixels within $5 \%$ to $15 \%$ of maximal intensity in the background ring immediately outside the spot of interest on the cDNA microarray. The "corrected signal intensity" for each spot is calculated as the "signal intensity" minus the "background signal."

Four microarray hybridizations were performed using total RNA samples prepared from individual VP of four young and four aged rats. The complete list of the 2400 genes, which were spotted as cDNAs on the Micromax microarray, can be found at http://www.nen.com/products/gene-list5.txt.

\section{Data Normalization and Identification of Differentially Expressed Genes Using t-Statistics}

Before data from the same slide or among different slides can be compared, the data must be normalized (ie, removing or adjusting for experimental [random] and systematic variations) (Yang et al, 2002). After within-slide normalization, all normalized log ratios were centered around zero. To compare expression levels across different slides, we applied the same normalization principles used for within-slide normalization. In this study, we chose to use all genes for normalization instead of using the microarray housekeeping gene pool for normalization for reasons that have been elaborated by Yang et al (2002). This approach, using the global median-intensity method, offers the most stability in terms of estimating spatialand intensity-dependent trends in the log ratios.

Differentially expressed genes associated with aging of the VP were then identified by computing two-sample, Welch $t$-statistics as previously described (Callow et al, 2000). Briefly, the normalized DNA microarray data of gene-expression profiles for VPs of young $\left(n_{1}=4\right)$ and old $\left(n_{2}=4\right)$ rats were presented as a matrix with columns corresponding to $n_{1}$ and $n_{2}$ and rows corresponding to 2400 genes
(cDNA spots on the Micromax microarray slide). The null hypothesis, $\mathrm{Hj}$, of equal mean expression of young and old rats for gene $j(j=1,2,3, \ldots, 2400)$ was tested. For gene $j, t$-value was calculated as follows.

$$
t_{j}=\frac{\chi_{1 j}-\chi_{2 j}}{\sqrt{\frac{s_{1 j}{ }^{2}}{n_{1}}+\frac{s_{2 j}{ }^{2}}{n_{2}}}}
$$

$\chi_{1 j}$ and $\chi_{2 j}$ denote the mean expression of gene $j$ in VPs of the $n_{1}$ young and $n_{2}$ old rats, respectively, and the $\mathrm{s}_{1 j}{ }^{2}$ and $\mathrm{s}_{2 j}{ }^{2}$ denote the variances of gene $j$ in VPs of the $n_{1}$ young and $n_{2}$ old rats, respectively. Large absolute $t$-values can be achieved by large differences between two mean values of gene expression for young and old rats and/or small variations among the samples within the same age group and suggests that the corresponding genes potentially showed significant differential expression in the VPs of young and old rats. A high absolute $t$-score is indicative of high significance in a differentially expressed gene in young and old VPs (negative $t$-scores indicate underexpression, whereas positive $t$-scores indicate overexpression of a gene in the aged compared with the young VPs). The evidence against the null hypothesis was assessed by calculating the $p$-value, which is the probability of error associated with rejecting the hypothesis of no difference between the two mean values of gene expression for young and old rats.

The $t$-statistics of all genes were presented in the $t$-value versus average A plot, in which the average A denotes the logarithm at base 2 for the square root of the multiple values of mean signals of Cy3 and Cy5. The data also were represented as a quantile-quantile plot, in which the ranked $t$ statistics were plotted against the corresponding quantiles of the standard normal distribution. Because of the probability of making a Type 1 error in the multiple $t$-testings from two groups of samples and 2400 genes, the Bonferroni correction to adjust the $p$-values by multiplying the $p$-value with 2400 .

\section{References}

Anawalt BD and Merriam GR (2001). Neuroendocrine aging in men. Andropause and somatopause. Endocrinol Metab Clin North Am 30:647-669.

Arunakaran J, Balasubramanian K, Srinivasan N, Aruldhas MM, and Govindarajulu P (1992). Interaction of androgens and prolactin on prostatic enzymes of the pyruvate-malate cycle involved in lipogenesis in castrated mature monkey. Macaca radiata Cytobios 70:33-40.

Bain J (2001). Andropause. Testosterone replacement therapy for aging men. Can Fam Physician 47:91-97.

Banerjee PP, Banerjee S, and Brown TR (2001). Increased androgen receptor expression correlates with development of age-dependent, lobe-specific spontaneous hyperplasia of the brown Norway rat prostate. Endocrinology 142:4066-4075.

Banerjee S, Banerjee PP, and Brown TR (2000). Castrationinduced apoptotic cell death in the Brown Norway rat prostate decreases as a function of age. Endocrinology 141:821832. 
Bettuzzi S, Strocchi P, Marinelli M, Astancolle S, Davalli P, and Corti A (1994). Gene relaxation and aging: Changes in the abundance of rat ventral prostate SGP-2 (clusterin) and ornithine decarboxylase mRNAs. FEBS Lett 348:255-258.

Brodsky FM, Chen CY, Knuehl C, Towler MC, and Wakeham DE (2001). Biological basket weaving: Formation and function of clathrin-coated vesicles. Annu Rev Cell Dev Biol 17:517-568.

Buchner J (1996). Supervising the fold: Functional principles of molecular chaperones. FASEB J 10:10-19.

Callow MJ, Dudoit S, Gong EL, Speed TP, and Rubin EM (2000). Microarray expression profiling identifies genes with altered expression in HDL-deficient mice. Genome Res 10: 2022-2029.

Cao SX, Dhahbi JM, Mote PL, and Spindler SR (2001). Genomic profiling of short- and long-term caloric restriction effects in the liver of aging male. Proc Natl Acad Sci USA 98:10630-10635.

Chinen K, Sudo K, Takahashi E, and Nakamura Y (1995). Isolation and mapping of the human beta-signal sequence receptor gene (SSR2). Cytogenet Cell Genet 70:215-217.

Cohen RJ, Fujiwara K, Holland JW, and McNeal JE (2001). Polyamines in prostatic epithelial cells and adenocarcinoma: The effects of androgen blockade. Prostate 49:278-284.

Costello LC, Franklin R, and Stacey R (1976). Mitochondrial isocitrate dehydrogenase and isocitrate oxidation of rat ventral prostate. Enzyme 21:495-506.

Cyriac J, Haleem R, Cai X, and Wang Z (2002). Androgen regulation of spermidine synthase expression in the rat prostate. Prostate 50:252-261.

Darsow T, Katzmann DJ, Cowles CR, and Emr SD (2001). Vps41p function in the alkaline phosphatase pathway requires homo-oligomerization and interaction with AP-3 through two distinct domains. Mol Biol Cell 12:37-51.

Davies KJ (2001). Degradation of oxidized proteins by the $20 \mathrm{~S}$ proteasome. Biochimie 83:301-310.

de Silva HV, Harmony JA, Stuart WD, Gil CM, and Robbins J (1990). Apolipoprotein J: Structure and tissue distribution. Biochemistry 29:5380-5389.

Feder ME and Hofmann GE (1999). Heat-shock proteins, molecular chaperones, and the stress response: Evolutionary and ecological physiology. Annu Rev Physiol 61:243-282.

Forman HJ and Torres M (2001). Redox signaling in macrophages. Mol Aspects Med 22:189-216.

Freeman C and Hopwood J (1992). Lysosomal degradation of heparin and heparan sulphate. Adv Exp Med Biol 313:121134.

Froissart R, Millat G, Mathieu M, Bozon D, and Maire I (1995). Processing of iduronate 2-sulphatase in human fibroblasts. Biochem J 309(Pt 2):425-430.

Fu J, Pirozzi G, Sanjay A, Levy R, Chen Y, Lemos-Chiarandini C, Sabatini D, and Kreibich G (2000). Localization of ribophorin II to the endoplasmic reticulum involves both its transmembrane and cytoplasmic domains. Eur J Cell Biol 79:219-228.

Gelperin D, Weigle J, Nelson K, Roseboom P, Irie K, Matsumoto K, and Lemmon S (1995). 14-3-3 proteins: Potential roles in vesicular transport and Ras signaling in Saccharomyces cerevisiae. Proc Natl Acad Sci USA 92:11539-11543.
Ghatak S and Ho SM (1996). Age-related changes in the activities of antioxidant enzymes and lipid peroxidation status in ventral and dorsolateral prostate lobes of noble rats. Biochem Biophys Res Commun 222:362-367.

Griffiths K (2000). Estrogens and prostatic disease. International Prostate Health Council Study Group. Prostate 45:87100.

Grodsky GM, Anderson CE, Coleman DL, Craighead JE, Gerritsen GC, Hansen CT, Herberg L, Howard CF Jr, Lernmark A, Matschinsky FM, Rayfield E, Riley WJ, and Rossini AA (1982). Metabolic and underlying causes of diabetes mellitus. Diabetes 31:45-53.

Gu F, Crump CM, and Thomas G (2001). Trans-Golgi network sorting. Cell Mol Life Sci 58:1067-1084.

Hatano K, Shimada T, Hiraiwa N, Nishimura M, and HaraNishimura I (1997). A rapid increase in the level of binding protein $(\mathrm{BiP})$ is accompanied by synthesis and degradation of storage proteins in pumpkin cotyledons. Plant Cell Physiol 38:344-351.

Heller JS, Fong WF, and Canellakis ES (1976). Induction of a protein inhibitor to ornithine decarboxylase by the end products of its reaction. Proc Natl Acad Sci USA 73:1858-1862.

Hellman R, Vanhove M, Lejeune A, Stevens FJ, and Hendershot LM (1999). The in vivo association of BiP with newly synthesized proteins is dependent on the rate and stability of folding and not simply on the presence of sequences that can bind to BiP. J Cell Biol 144:21-30.

Heydari AR, Conrad CC, and Richardson A (1995). Expression of heat shock genes in hepatocytes is affected by age and food restriction in rats. J Nutr 125:410-418.

Hinkle GJ (1988). Prostate gland and epididymis phosphatase isoenzymes: Comparisons of young adult and aged rats. Gerontology 34:120-127.

Ho SM and Lau KM (2002). DNA microarrays in prostate cancer. Curr Urol Rep 3:53-60.

Ibba M and Soll D (2000). Aminoacyl-tRNA synthesis. Annu Rev Biochem 69:617-650.

Isaacs JT (1984). The aging $\mathrm{ACl} / \mathrm{Seg}$ versus Copenhagen male rat as a model system for the study of prostatic carcinogenesis. Cancer Res 44:5785-5796.

Jackson RJ and Wickens M (1997). Translational controls impinging on the $5^{\prime}$-untranslated region and initiation factor proteins. Curr Opin Genet Dev 7:233-241.

July LV, Akbari M, Zellweger T, Jones EC, Goldenberg SL, and Gleave ME (2002). Clusterin expression is significantly enhanced in prostate cancer cells following androgen withdrawal therapy. Prostate 50:179-188.

Karsten SL, Van Deerlin VM, Sabatti C, Gill LH, and Geschwind DH (2002). An evaluation of tyramine signal amplification and archived fixed and frozen tissue in microarray gene expression analysis. Nucleic Acids Res 30:E4.

Klionsky DJ and Emr SD (2000). Autophagy as a regulated pathway of cellular degradation. Science 290:1717-1721.

Kowluru R, Bitensky MW, Kowluru A, Dembo M, Keaton PA, and Buican T (1989). Reversible sodium pump defect and swelling in the diabetic rat erythrocyte: Effects on filterability and implications for microangiopathy. Proc Natl Acad Sci USA 86:3327-3331. 
Lee CK, Weindruch R, and Prolla TA (2000). Gene-expression profile of the ageing brain in mice. Nat Genet 25:294-297.

Lee HM, Greeley GH Jr, and Englander EW (2001). Ageassociated changes in gene expression patterns in the duodenum and colon of rats. Mech Ageing Dev 122:355-371.

Lenaz G, D’Aurelio M, Merlo PM, Genova ML, Ventura B, Bovina C, Formiggini G, and Parenti CG (2000). Mitochondrial bioenergetics in aging. Biochim Biophys Acta 1459:397404.

Liszewski MK, Post TW, and Atkinson JP (1991). Membrane cofactor protein (MCP or CD46): Newest member of the regulators of complement activation gene cluster. Annu Rev Immunol 9:431-455.

Ly DH, Lockhart DJ, Lerner RA, and Schultz PG (2000). Mitotic misregulation and human aging. Science 287:24862492.

Malins DC, Johnson PM, Wheeler TM, Barker EA, Polissar NL, and Vinson MA (2001). Age-related radical-induced DNA damage is linked to prostate cancer. Cancer Res 61:60256028.

Marinelli M, Quaglino D, Bettuzzi S, Strocchi P, Davalli P, and Corti A (1994). Increased levels of clusterin mRNA in the ventral prostate of the aging rat are associated to increases in cuboidal (atrophic) cell population and not to changes in apoptotic activity. Biochem Cell Biol 72:515-521.

Merker K, Stolzing A, and Grune T (2001). Proteolysis, caloric restriction and aging. Mech Ageing Dev 122:595-615.

Merrick WC (1992). Mechanism and regulation of eukaryotic protein synthesis. Microbiol Rev 56:291-315.

Mittal BV, Amin MB, and Kinare SG (1989). Spectrum of histological lesions in 185 consecutive prostatic specimens. J Postgrad Med 35:157-161.

Morales A and Tenover JL (2002). Androgen deficiency in the aging male: When, who, and how to investigate and treat. Urol Clin North Am 29:975-982.

Morley JE and Perry HM III (2000). Androgen deficiency in aging men: role of testosterone replacement therapy. J Lab Clin Med 135:370-378.

Mullins C and Bonifacino JS (2001). Structural requirements for function of yeast GGAs in vacuolar protein sorting, alpha-factor maturation, and interactions with clathrin. Mol Cell Biol 21:7981-7994.

Murakami Y, Matsufuji S, Kameji T, Hayashi S, Igarashi K, Tamura T, Tanaka K, and Ichihara A (1992). Ornithine decarboxylase is degraded by the $26 \mathrm{~S}$ proteasome without ubiquitination. Nature 360:597-599.

Nowotny V and Nierhaus KH (1982). Initiator proteins for the assembly of the $50 \mathrm{~S}$ subunit from Escherichia coli ribosomes. Proc Natl Acad Sci USA 79:7238-7242.

Pang ST, Dillner K, Wu X, Pousette A, Norstedt G, and Flores-Morales A (2002). Gene expression profiling of androgen deficiency predicts a pathway of prostate apoptosis that involves genes related to oxidative stress. Endocrinology 143:4897-4906.

Pegg AE (1986). Recent advances in the biochemistry of polyamines in eukaryotes. Biochem J 234:249-262.

Post TW, Liszewski MK, Adams EM, Tedja I, Miller EA, and Atkinson JP (1991). Membrane cofactor protein of the complement system: Alternative splicing of serine/threonine/ proline-rich exons and cytoplasmic tails produces multiple isoforms that correlate with protein phenotype. J Exp Med 174:93-102.

Prescott JL and Tindall DJ (1998). Clathrin gene expression is androgen regulated in the prostate. Endocrinology 139: 2111-2119.

Prins GS, Jung MH, Vellanoweth RL, Chatterjee B, and Roy AK (1996). Age-dependent expression of the androgen receptor gene in the prostate and its implication in glandular differentiation and hyperplasia. Dev Genet 18:99-106.

Rao KM and Cohen HJ (1991). Actin cytoskeletal network in aging and cancer. Mutat Res 256:139-148.

Rattan SI (1991). Protein synthesis and the components of protein synthetic machinery during cellular aging. Mutat Res 256:115-125.

Riis B, Rattan SI, Clark BF, and Merrick WC (1990). Eukaryotic protein elongation factors. Trends Biochem Sci 15:420424.

Roth D, Birkenfeld J, and Betz H (1999). Dominant-negative alleles of 14-3-3 proteins cause defects in actin organization and vesicle targeting in the yeast Saccharomyces cerevisiae. FEBS Lett 460:411-416.

Sanchez-Visconti G, Herrero L, Rabadan M, Pereira I, and Ruiz-Torres A (1995). Ageing and prostate: Age-related changes in androgen receptors of epithelial cells from benign hypertrophic glands compared with cancer. Mech Ageing Dev 82:19-29.

Schmid SL (1997). Clathrin-coated vesicle formation and protein sorting: An integrated process. Annu Rev Biochem 66:511-548.

Schreiber RD (1984). The chemistry and biology of complement receptors. Springer Semin Immunopathol 7:221-249.

Schulman CC (2000). The aging male: A challenge for urologists. Curr Opin Urol 10:337-342.

Serafini T, Orci L, Amherdt M, Brunner M, Kahn RA, and Rothman JE (1991). ADP-ribosylation factor is a subunit of the coat of Golgi-derived COP-coated vesicles: A novel role for a GTP-binding protein. Cell 67:239-253.

Shen R, Su ZZ, Olsson CA, and Fisher PB (1995). Identification of the human prostatic carcinoma oncogene PTI-1 by rapid expression cloning and differential RNA display. Proc Natl Acad Sci USA 92:6778-6782.

Shiosaka T and Saunders GF (1982). Differential expression of selected genes in human leukemia leukocytes. Proc Natl Acad Sci USA 79:4668-4671.

Shringarpure R, Grune T, and Davies KJ (2001). Protein oxidation and $20 \mathrm{~S}$ proteasome-dependent proteolysis in mammalian cells. Cell Mol Life Sci 58:1442-1450.

Sitte N, Merker K, Von Zglinicki T, and Grune T (2000a). Protein oxidation and degradation during proliferative senescence of human MRC-5 fibroblasts. Free Radic Biol Med 28:701-708.

Sitte N, Merker K, Von Zglinicki T, Grune T, and Davies KJ (2000b). Protein oxidation and degradation during cellular senescence of human BJ fibroblasts: Part I-effects of proliferative senescence. FASEB J 14:2495-2502.

Smith RC, Litwin MS, Lu Y, and Zetter BR (1995). Identification of an endogenous inhibitor of prostatic carcinoma cell growth. Nat Med 1:1040-1045. 
Stronge VS, Saito Y, Ihara Y, and Williams DB (2001). Relationship between calnexin and BiP in suppressing aggregation and promoting refolding of protein and glycoprotein substrates. J Biol Chem 276:39779-39787.

Sudo K, Takahashi E, and Nakamura Y (1995). Isolation and mapping of the human EIF4A2 gene homologous to the murine protein synthesis initiation factor 4A-II gene Eif4a2. Cytogenet Cell Genet 71:385-388.

Takei K and Haucke V (2001). Clathrin-mediated endocytosis: membrane factors pull the trigger. Trends Cell Biol 11:385-391.

Tseng GC, Oh MK, Rohlin L, Liao JC, and Wong WH (2001). Issues in cDNA microarray analysis: Quality filtering, channel normalization, models of variations and assessment of gene effects. Nucleic Acids Res 29:2549-2557.

Turunen O, Wahlstrom T, and Vaheri A (1994). Ezrin has a $\mathrm{COOH}$-terminal actin-binding site that is conserved in the ezrin protein family. J Cell Biol 126:1445-1453.

Van Valkenburgh $\mathrm{H}$, Shern JF, Sharer JD, Zhu X, and Kahn RA (2001). ADP-ribosylation factors (ARFs) and ARF-like 1 (ARL1) have both specific and shared effectors: characterizing ARL1-binding proteins. J Biol Chem 276:22826-22837.

Verbeke P, Clark BF, and Rattan SI (2000). Modulating cellular aging in vitro: Hormetic effects of repeated mild heat stress on protein oxidation and glycation. Exp Gerontol 35:787-794.

Ward JM, Reznik G, Stinson SF, Lattuada CP, Longfellow DG, and Cameron TP (1980). Histogenesis and morphology of naturally occurring prostatic carcinoma in the $\mathrm{ACl}$ / segHapBR rat. Lab Invest 43:517-522.
Weber J and Senior AE (1997). Catalytic mechanism of F1-ATPase. Biochim Biophys Acta 1319:19-58.

Weindruch R, Kayo T, Lee CK, and Prolla TA (2001). Microarray profiling of gene expression in aging and its alteration by caloric restriction in mice. J Nutr 131:918S-923S.

Weindruch R, Kayo T, Lee CK, and Prolla TA (2002). Gene expression profiling of aging using DNA microarrays. Mech Ageing Dev 123:177-193.

Williams-Ashman HG and Canellakis ZN (1979). Polyamines in mammalian biology and medicine. Perspect Biol Med 22:421-453.

Willis TG, Zalcberg IR, Coignet LJ, Wlodarska I, Stul M, Jadayel DM, Bastard C, Treleaven JG, Catovsky D, Silva ML, and Dyer MJ (1998). Molecular cloning of translocation $t(1 ; 14)(q 21 ; q 32)$ defines a novel gene (BCL9) at chromosome 1q21. Blood 91:1873-1881.

Yang YH, Dudoit S, Luu P, Lin DM, Peng V, Ngai J, and Speed TP (2002). Normalization for cDNA microarray data: A robust composite method addressing single and multiple slide systematic variation. Nucleic Acids Res 30:e15.

Zhu N, Pewitt EB, Cai X, Cohn EB, Lang S, Chen R, and Wang Z (1998). Calreticulin: An intracellular $\mathrm{Ca}++-$-binding protein abundantly expressed and regulated by androgen in prostatic epithelial cells. Endocrinology 139:4337-4344. 